\title{
Proposed Model for Carrying Lightweight Loads in Forging Industries
}

\author{
Basil Sunny, Richu Thomas \\ Mechanical Department AmalJyothi College of Engg. Kanjirappally, India \\ Mechanical Engineering AmalJyothi college of Engg. Kanjirappally, India
}

\begin{abstract}
This paper proposing a model for carrying light loads in forging industries. In industries like forging the job has to be carried between different units for various operations. The job carrying may be at high temperature and the job has to keep in the particular temperature for the forging purpose. The carrying of load and the placing of job over the hammer or to any other unit is a major factor. To reduce the time and the risk in transporting and placing the job over the hammer or to the furnace the carrier has a major role. By this paper I am proposing a model that help the workers to reduce their difficulty of transportation and to reduce the risk in placing the job over the hammer or in furnace.
\end{abstract}

Keywords: forging, carrier, furnace, transportation, temperature.

\section{INTRODUCTION}

Forging is a process of making desired shape by compressive force on the work piece. The work piece is subjected to hammering in the hammer. By hammering on the work piece the desired shape can be adopted and the process of making the desired shape by hammering is called forging process. The forging is carried out mainly for metals like iron, steel, aluminium, titanium etc. The steel forging is highly productive. The forging is used to make both large (weight above 100kg) and small (weight below 100kg) products. For the forging purpose the billets has to be heated to a required temperature before pressing or hammering. After heating the work piece to the required temperature, the work piece will be transported to the forging unit for hammering. The job will be of different weight and size. To transport heavy weight to the furnace and to hammer, the crane and fork are used. It is the easiest way of loading the heavy materials to the hammer and to the furnace.

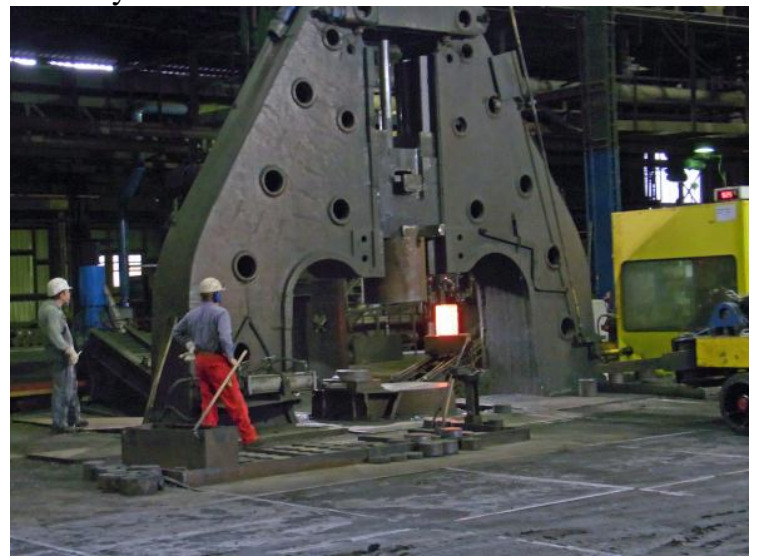

The work piece will be of weight varying from $100 \mathrm{~kg}$ to $950 \mathrm{~kg}$ and at a heat of around $900^{\circ} \mathrm{C}$. So the carrying of the job is highly risky. To carry the load of weight below $100 \mathrm{~kg}$ usual trolley is used. Using the trolley the hot work piece is transported to the furnace from hammer and vice versa. When the trolley reaches the furnace or hammer the worker has to put the work piece at the floor. Using a tong the job in the floor is holds by two or three workers and they will throw the job to the furnace or to the hammer. The process using the tong is highly risky and also there is chance of losing the temperature of the job before hammering.

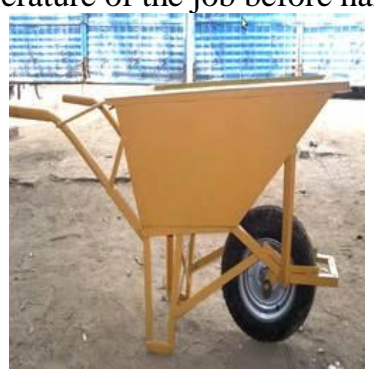




\section{Proposed Model}

To avoid the risk and the difficult in the transportation and difficulty in placing the job over the furnace or the hammer can be rectified by the proposed model.

By the new model of the carrier the risk and difficulty in placing the job over the hammer or the furnace can be rectified. By using the new model the number of workers can be reduced, the use of tong and the throwing of job using the tong can also be avoided and there by the difficulty and risk can be avoided.

The new model contains a pedal for rotating a disk that converts the rotating motion to linear motion. The disk is connected to a rod which is connected to the plate, where the job has to be carried.

The plate in the box like structure is movable in a linear motion. So the rotating motion of the disk is converted to the linear motion in the plate. The plate is used to carry the job which is placed inside a box like metallic structure. It helps to protect the job from falling down while transporting from different units.

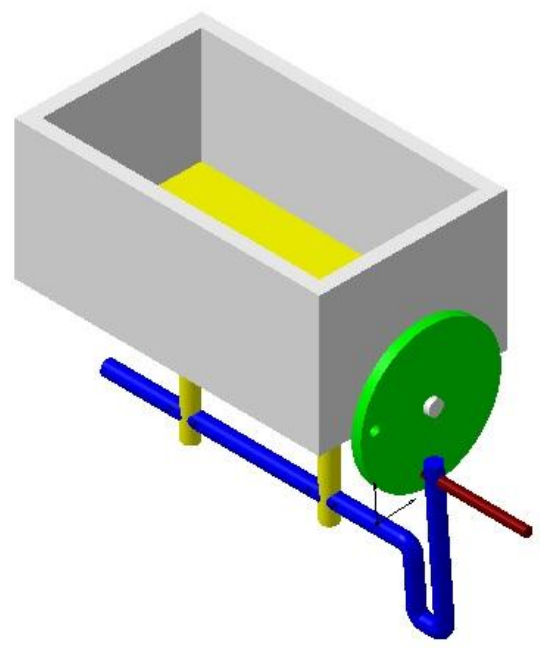

The above figure shows the proposed model for the carrying load of weight under 100kg.

The model contains different parts such as pedal, disk, connecting rod, box, and plate connected to the connecting rod. The connecting rod is used to connect the plate and the rotating disk. This connecting rod converts the rotating motion of the disk to the linear motion of the plate. It is a simple mechanism helps to lift the job to the required height without any mechanical advantage. The model helps to reduce the time required to transport the job, reduce the risk and difficulty of using tong to place the job over the hammer or to the furnace. The positioning of the job to the furnace and to the hammer for hammering has to be done, a long fork has to be used.

\section{WORKING OF THE NEW MODEL}

The new model consist of different parts and each part having different function which makes the process much easier. The work piece will be dragged to the carrier from the furnace or from the hammer. The plate will at the lowest position at the moment the job is placed inside the carrier and also during the transportation of the job to the next unit. When the work piece is at furnace or hammer the disk has to be rotated using the pedal where the connecting rod will convert this rotation motion to the linear motion of the plate on the carrier.

The model is designed in a way that the,

$$
\mathbf{L}=\mathbf{D}
$$

" $\mathbf{L}=$ Distance of plate to be raised in the carrier.

"D = the distance taken by the hand wheel to complete a semicircle"

So when the disk is rotated once the connecting rod also lift and along with the connecting rod the plate also lift to the top. The operation of vertical movement of the plate as the rotating wheel rotates, is similar to the crank piston mechanism. By this mechanism the rotary motion can be converted in to linear motion. The rotating wheel is similar to the crank rotation and the plate that carrying the job is in linear motion, similar to piston. The connecting rod attached to the hand pedal will make rotation motion and which is connected to the connecting rod, connected to the plate. So the operation will be similar to that of piston and crank mechanism. There included a hole in the disk and in the carrier to lock the disk to resist from the further rotating of the disk.

When the plate reached the top position of the carrier, then the height of plate will be equal or greater than the hammer or furnace height. So using the long fork the positioning of the job can be done.

This will reduce the time consumption and the risk of the workers.

Different views of the model is showed in the figure. 


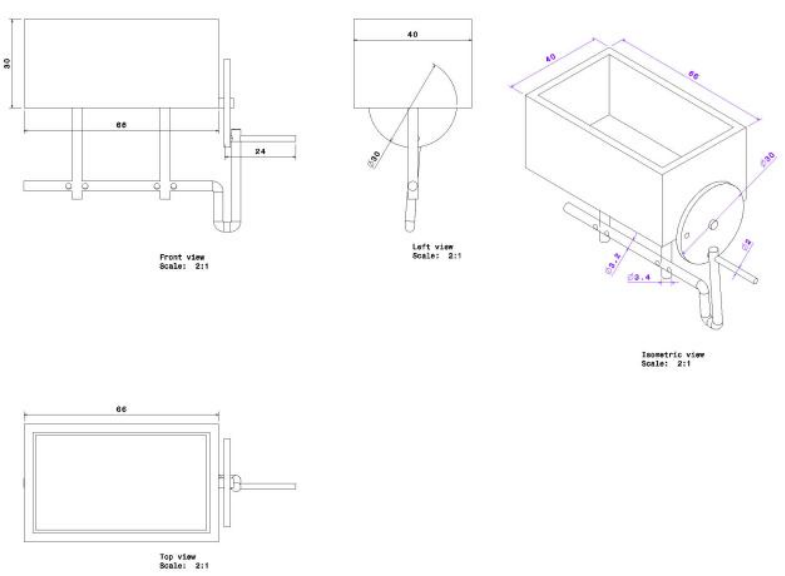

The dimension of the parts can be altered according to the industries and the type of shape and size of the job used.

\section{MATERIAL SELECTION}

The material selection for the model is a major factor to be considered. Many factors has to be considered while selecting the material for the making of the model.

The material should be economic, heat resistant as high temperature work pieces are carrying, light weight, and ease of manufacturing of the model.

By studying various materials, the most suitable material that can be used for making the model is "mild steel"

Mild steel is one of the common of all metals and one of the least expensive steel used. It is very durable, relatively hard, easily weld able and easily annealed. The mild steel is used in forging units and in many industrial areas, because is having a high tensile strength of $525 \mathrm{MPa}$. Mild steel having high dimensional accuracy, and another property is that, it can be easily installed. The thermal expansion coefficient of mild steel is $\left(12.6 \times 10^{-6}\right.$ $1{ }^{\circ} \mathrm{C}$.

The properties of the mild steel makes it unique from other metals. As it is economical, durable and relatively hard, it can be selected for the model.

The components of the mild steel are

\begin{tabular}{|l|l|}
\hline Carbon & $0.16-0.18 \%$ \\
\hline Silicon & $0.40 \% \max$ \\
\hline Manganese & $0.70-0.90 \%$ \\
\hline Sulphur & $0.04 \% \max$ \\
\hline Phosphorus & $0.040 \% \max$ \\
\hline
\end{tabular}

\section{CONCLUSION}

In the forging industries the difficulty and risk that facing during the transportation of the light weight (below 100kg) is studied. By studying the difficulties new model is proposed, which helps to reduce the difficulties and risk of the works while transporting and lifting the work piece to the hammer and to the furnace. The proposed model help to reduce the time consumption of the workers and the number of workers can be reduced.

\section{REFERENCE}

[1] Dr. Taylan Altan, Professor And Director, And Mayur Deshpande Erc For Net Shape Forming, The Ohio State University, "Selection Of Die Materials And Surface Treatments For Increasing Die Life In Hot And Warm Forging”, Paper No 644-Fia Tech Conference, April 2011.M. Young, The Technical Writer's Handbook. Mill Valley, CA: University Science, 1989.

[2] Markus Knobloch, Jacqueline Pauli, Mario Fontana, Influence of the strain-rate on the mechanical properties of mild carbon steel at elevated temperatures, Materials \& Design, Volume 49, August 2013, Pages 553-565.

[3] Robert H. Harcout "Elementary Forge Practice", Textbook for Technical and Vocational Schools.

[4] Owain Pedgley, Materials Selection for Product Experience: New Thinking, New Tools, Fundamentals of Materials and Design, 2014, Pages 337-349.

[5] S. Sinaie, A. Heidarpour, X.L. Zhao, Mechanical properties of cyclically-damaged structural mild steel at elevated temperatures, Construction and Building Materials, Volume 52, 15 February 2014, Pages 465-472.

[6] S.P. Chiew, M.S. Zhao, C.K. Lee, Mechanical properties of heat-treated high strength steel under fire/post-fire conditions, Journal of Constructional Steel Research, Volume 98, July 2014, Pages 12-19. 